\title{
Bone mineral density levels in elite female athletes
}

\author{
R L Wolman
}

Exercise affects the bone mineral density (BMD) of female athletes in several important ways. Exercise can have a direct action on bone. The type and intensity of exercise and the anatomical site where the stress is applied can all be influential. Exercise can also act indirectly by modifying the function of the hypothalamicpituitary-ovarian axis, leading to reduced oestrogen status. Finally, illicit drugs used by some athletes, such as anabolic steroids and growth hormone, may also influence BMD.

The relation of BMD with exercise and low oestrogen status is reviewed together with the link which exists between exercise and amenorrhoea.

\section{Exercise and bone mineral density}

Wolff was amongst the first to recognise that bone tissue adapts in response to the functional forces acting upon it. More recently, the importance of physical stress in maintaining bone mineralisation has been appreciated. The type of physical stress necessary to stimulate bone tissue has not been fully identified, however.

Weightbearing exercise is important in maintaining adequate stimulation to the skeleton. Negative calcium balance and significant bone loss occur in patients enduring prolonged bed rest. ${ }^{2}$ Similar losses are also seen in astronauts, ${ }^{3}$ who are exposed to a gravity free environment. Furthermore, studies by Nilsson and Westlin and Jacobson et al have suggested that swimmers achieve fewer skeletal benefits than athletes doing weightbearing sports. ${ }^{45}$

Several studies have shown higher levels of BMD in athletes than in sedentary controls. ${ }^{4}$ These studies have shown that exercise exerts a local effect on the skeleton, at the site of maximum stress. For example, the cortical BMD in the wrist of the playing arm in tennis players can be up to $30 \%$ higher than in the other arm, ${ }^{67}$ whereas in runners there are increases in the BMD of the os calcis. ${ }^{8}$ The trabecular BMD of the lumbar spine is also increased in runners, ${ }^{9}$ but even larger increases at this site are seen in rowers, ${ }^{10}$ whose sport requires intensive back exercise.

It might be argued that the higher bone densities seen in athletes have allowed them to undertake intensive training rather than being secondary to it. The most effective way of showing that the BMD increases in response to exercise is from prospective data. Longitudinal studies have shown increases in BMD with exercise both in athletes ${ }^{8}$ and in postmenopausal women. ${ }^{11}$ Work by Dalsky et al with postmenopausal women suggests that although bone responds to exercise stimulation, the benefit is lost once the exercise is discontinued. ${ }^{12}$

Recent studies have investigated the relation between measurements of fitness and BMD. Aerobic fitness, measured as the maximum oxygen uptake during a graded exercise test $\left(\mathrm{Vo}_{2} \mathrm{max}\right)$, has been measured in several studies. A weak, positive correlation with $B M D$ was found in those studies that estimated $\mathrm{Vo}_{2} \max$ from the heart rate. ${ }^{13} 14$ Studies that measured $\mathrm{Vo}_{2} \mathrm{max}$ directly, ${ }^{12}{ }^{15}$ however, found no correlation in postmenopausal women and therefore, at best, aerobic fitness is only a weak determinant of BMD. Significant correlations between BMD and muscle strength have also been shown. Cross sectional studies have shown relations between spinal bone density and isometric back strength ${ }^{16}$ and between spinal and forearm bone density and isometric grip strength, ${ }^{15}$ but the type and frequency of muscle strengthening exercises necessary to increase BMD have not yet been determined.

Stress loading experiments in animals have identified three strain variables that influence bone remodelling. ${ }^{17}$ The peak strain magnitude (the size of the force applied to the bone), the strain rate (the frequency at which the force is applied), and strain distribution (the direction in which the force is applied) have all been shown to affect the osteogenic stimulus.

In humans there are still uncertainties about the type, frequency, and intensity of exercise that provides the maximum anabolic stimulus. With improved understanding it might be possible to devise specific exercise protocols that could be used in the prevention or management of osteoporosis.

\section{Exercise and menstrual status}

Amenorrhoea was first recognised as a feature of athletes in heavy training about 10 years ago. Before this it was unusual for women to train hard enough to develop amenorrhoea. In recent years, however, with women athletes training as hard as their male counterparts, this disorder has become increasingly recognised.

Amenorrhoea occurs with endurance but not power training-for example, in athletics it occurs among the marathon runners but not among the sprinters. It is related to the intensity of training. The incidence of amenorrhoea among women who run 20 miles/week is about $20 \%$, ${ }^{18}$ whereas in those running 80 miles/week it is about $50 \%$.
Centre, Northwick Park Hospital, Harrow, Middlesex HA1 3UJ

R L Wolman 


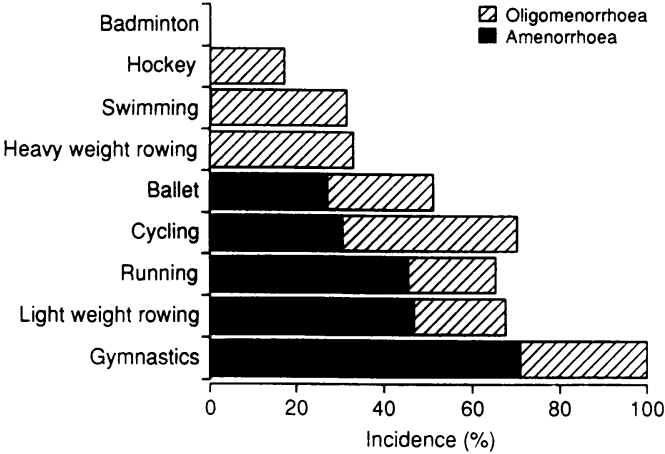

Figure 1 Incidence of menstrual irregularity in different sports.

Menstrual irregularity is also linked with the diet. Lightweight women rowers must be below $59 \mathrm{~kg}$ in order to compete and therefore may require energy restricted diets so that they 'make the weight'. Although they train similarly to their heavyweight counterparts, the incidence of amenorrhoea among the lightweights is significantly higher. ${ }^{19}$ Amenorrhoea among ballerinas, who frequently adopt low energy diets, is also well recognised. The combination of endurance training and energy restriction will lead to major changes in body composition and in particular, a reduction in body fat. This will influence their menstrual status.

There is evidence to suggest that intense training in childhood may delay the onset of puberty and lead to primary amenorrhoea. ${ }^{20}$ In some cases menarche may be delayed beyond the age of 20. This may have adverse consequences not only on BMD but also on skeletal maturation. ${ }^{21}$ Intense training in the immediate, postadolescent period is more likely to lead to secondary amenorrhoea than in older athletes in their late twenties.

The age of the athlete, therefore, together with their training intensity, and the degree of energy restriction are the three most important factors that determine the incidence of amenorrhoea seen in each sport (fig 1). ${ }^{19}$

Menstrual status and bone mineral density The importance of oestrogen deficiency in postmenopausal osteoporosis was identified by Albright. ${ }^{22}$ Since then studies in several conditions have shown the importance of oestrogen in protecting premenopausal women from developing low bone mass.

In oophorectomised patients under the age of 45 Aitken $e t$ al found bone loss occurring within three to six years of the operation. ${ }^{23}$ Oestrogen treatment effectively prevented bone loss if started within two months of oophorectomy. When treatment was delayed beyond six years Lindsay et al showed that bone loss was partially or completely irreversible. ${ }^{24}$

Luteinising hormone releasing hormone agonists, used for the treatment of endometriosis, induce a reversible suppression of gonadotrophin secretion which, in turn, produces hypooestrogenaemia. Treatment is usually given for a maximum of six months, throughout which there is a fall in trabecular BMD. ${ }^{25}$ When treatment is stopped ovarian function returns to normal and the BMD returns to its pretreatment level within six months. ${ }^{26}$

Women with hyperprolactinaemia also develop amenorrhoea with significant reductions in spinal BMD. ${ }^{27} 28$ Patients with anorexia nervosa and amenorrhoea also have decreased BMD, ${ }^{29-31}$ which is partially offset in those patients who maintain high exercise levels. In some cases the BMD may be so low that vertebral crush fractures develop. ${ }^{29}$

There is therefore abundant evidence to show that low oestrogen status in the premenopausal woman has an adverse effect on bone mineral density. Uncertainty still remains about the duration of amenorrhoea necessary to cause irreversible reductions in BMD. It would seem that more than six months of amenorrhoea is necessary. ${ }^{26}$

\section{Athletic amenorrhoea and bone mineral density}

Although amenorrhoea in athletes was recognised in the late seventies, it was initially thought that high levels of exercise would protect the skeleton from the adverse effects of low oestrogen status. In 1984, however, three studies of amenorrhoeic athletes showed reduced BMD in the lumbar spine, a site where trabecular bone predominates. ${ }^{28} 3233$ The most impressive of these was that by Drinkwater $e t$ $a l$, who studied 14 amenorrhoeic and 14 eumenorrhoeic runners and found that the vertebral mineral density, measured by dual photon absorptiometry, was significantly lower in the amenorrhoeic group, even though they trained harder ( 42 miles/week $v 25$ miles/week). ${ }^{32}$

Trabecular bone density is therefore reduced in women with amenorrhoea. This bone loss is less marked in amenorrhoeic athletes than it is in amenorrhoeic women doing little or no exercise. ${ }^{34}$ Furthermore, when the exercise is targeted at the spine, as it is in rowers, spinal bone loss is further attenuated and is similar to the level seen in eumenorrhoeic non-athletes. ${ }^{10}$ This emphasises the localised nature of the skeletal response to exercise.

The response of cortical bone to low oestrogen status is less dramatic than that of trabecular bone, which remodels much more rapidly than cortical bone. This has been shown in oophorectomised women ${ }^{35}$ and more recently among amenorrhoeic athletes. ${ }^{32} 36$ The duration of amenorrhoea in athletes may not be sufficiently long to produce changes, however.

Longitudinal studies on athletic amenorrhoea have also been performed. ${ }^{37} 38$ Drinkwater ${ }^{37}$ restudied nine of the 14 amenorrhoeic and seven of the 14 eumenorrhoeic athletes from her original study. ${ }^{32}$ The lumbar spine BMD was measured 16 months after the original measurements. Seven of the nine amenorrhoeic athletes had regained menses and in this group the BMD had increased by $6.3 \%$. In the two who remained amenorrhoeic the BMD had decreased by $3.4 \%$. There was no change in BMD in the women who remained eumenorrhoeic. Lindberg showed that in a 15 month period spinal BMD in four athletes who regained their menses 


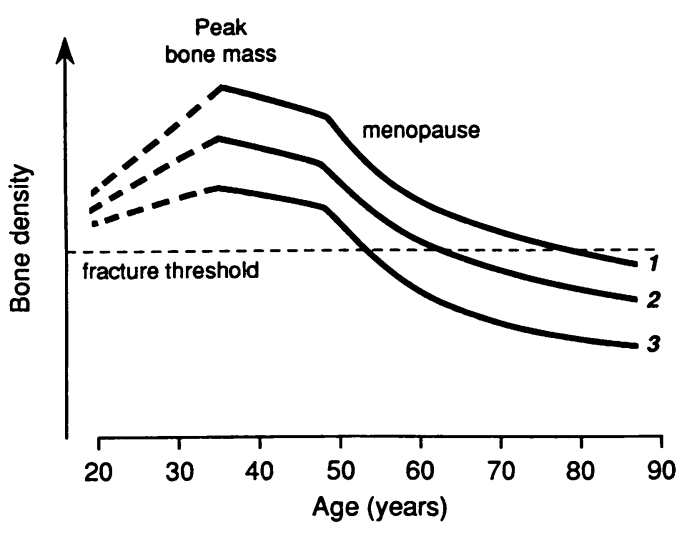

Figure 2 Theoretical changes in bone density with age in eumenorrhoeic, sedentary women (2), eumenorrhoeic athletes (1), and amenorrhoeic athletes (3).

increased by an average of $6.6 \%$, whereas in three who remained amenorrhoeic it decreased by an average of $1 \cdot 3 \% .{ }^{38}$

Some amenorrhoeic athletes develop nutritional deficiencies. Many on energy restricted diets become energy deficient. They may also be on diets deficient in calcium, vitamins, zinc $^{39}$ and other trace elements. Such deficiencies might also have an adverse effect on BMD and the attainment of peak bone mass. ${ }^{40}$

Amenorrhoea in athletes is associated with reduction in trabecular, but not cortical, bone mineral density. With short episodes of amenorrhoea $B M D$ recovers, at least partially, with return of the menses. Athletes with persistent amenorrhoea continue to lose bone mineral, and it is this group who may be at risk of osteoporosis.

\section{Athletic amenorrhoea and fractures}

Cann using computed tomographic scanning defined the level of trabecular bone density in the spine which represents a threshold, above which crush fractures are not likely to occur. ${ }^{41}$ This level was $110 \mathrm{mg} / \mathrm{cm}^{3}$, whereas subjects with a spinal bone density below $70 \mathrm{mg} / \mathrm{cm}^{3}$ seemed to have a high risk of fracture, including multiple fractures. With bone densities below $110 \mathrm{mg} / \mathrm{cm}^{3}$ the risk of fracture increases inversely with the bone density. Most women tend to reach this fracture threshold by their mid-sixties (fig 2). Among our series of 25 athletes with amenorrhoea, we found two with spinal bone densities below the fracture threshold, although, so far, neither has developed fractures. Drinkwater also found two amenorrhoeic athletes with spinal bone densities below the fracture threshold. ${ }^{32}$ No study has so far

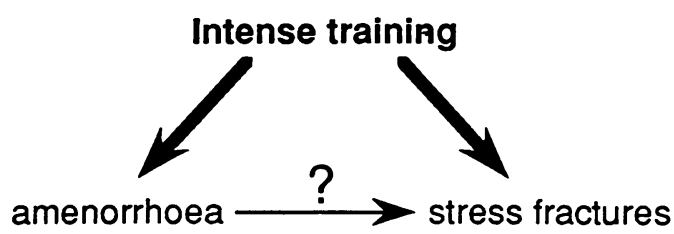

Figure 3 Relation between intense training, amenorrhoea, and stress fractures. reported the occurrence of osteoporotic fractures amongst amenorrhoeic athletes, but they have been described amongst women with amenorrhoea due to anorexia nervosa (see above).

Athletes with amenorrhoea may also be at increased risk of developing stress fractures. Lindberg found that stress fractures in general were more common among the amenorrhoeic than the eumenorrhoeic runners. ${ }^{33}$ The amenorrhoeic runners also trained harder and ran greater distances each week, however. Marcus also found a much higher incidence of stress fractures in a small group of amenorrhoeic runners than in their eumenorrhoeic counterparts. ${ }^{34}$ Although they were well matched for aerobic capacity, it is uncertain whether they were also matched for training intensity. Intense training increases the risk of both amenorrhoea and stress fractures and this may be the reason why such fractures appear to be more common in the amenorrhoeic athlete (fig 3).

Premature osteoporosis in later life is the chief concern relating to athletic amenorrhoea. Athletes with prolonged amenorrhoea in their twenties may never attain the expected peak bone mass in their thirties and might therefore reach the menopause with a reduced bone mass reserve. They may then have difficulty withstanding the rapid bone losses that occur during the menopausal years and cross the fracture threshold prematurely (fig 2 ).

\section{Conclusions}

There are few longitudinal data on the consequences of bone density changes in athletic amenorrhoea. Encouraging studies by Drinkwater and Lindberg have suggested that bone density loss due to amenorrhoea may be reversible in women with only short lived disturbances of menstruation. ${ }^{37} 38$ They studied small numbers of women, however, and the results must be interpreted with caution. Irreversible reductions in bone density may occur if amenorrhoea is prolonged, but the time length necessary has not been clearly defined except in older women after oophorectomy. ${ }^{24}$

Manipulation of the training schedule or the diet, or both, in amenorrhoeic athletes may allow normal menses to return either permanently or intermittently. This may be sufficient to protect the BMD. It is difficult to persuade many athletes to reduce their training mileage, however, and in such circumstances it may be appropriate to offer hormone replacement therapy. In the United States such treatment is used commonly in the management of amenorrhoeic athletes, but little information exists on the benefits in this age group. There is also little information on the effect of amenorrhoea in sports other than running, but there is some evidence that the risk of osteoporosis may be modified by the type of sport performed.

Eumenorrhoeic athletes have levels of spinal BMD that are up to $15 \%$ higher than that found in the general population. Exercise may provide an effective way of enhancing peak bone mass and hence delaying the time taken to reach the fracture threshold (fig 2). This benefit is lost, 
however, if the exercise is of sufficient intensity to lead to amenorrhoea. In older women exercise may also be an effective method of reducing or preventing postmenopausal bone loss. Whether exercise might also be of benefit in reducing the risk of steroid induced osteoporosis has not so far been studied.

At present it is not possible to specify the type, intensity or duration of exercise that provides the maximum anabolic stimulus to bone. For the future, studies of athletes from different sports and identification of those training habits which are associated with anabolic effects on bone should be helpful in developing exercise strategies for reducing the incidence of osteoporotic fractures in later life.

I thank Dr J Reeve, Head of the Bone Research Group, CRC and Dr M G Harries, honorary director of the British Olympic Medical Centre, for their help and advice.

1 Wolff J D. Das Geretz der Transformation der Knochen. Berlin: Hirchwald, 1892

2 Mazess R B, Whedon G D. Immobilization and bone. Calcif Tissue Int 1983; 35: 265-7.

3 Whedon G D, Lutwak L, Rambaut P, et al. Effect of weightlessness on mineral metabolism; metabolic studies on skylab orbital space flights. Calcif Tissue Int 1976; 21 : S423-30.

4 Nilsson B E, Westlin N E. Bone density in athletes. Clin Orthop 1971; 77: 179-82.

5 Jacobson P C, Beaver W, Grubb S A, Taft T N, Talmage R $V$. Bone density in women: college athletes and older $V$. Bone density in women: college athletes
athletic women. $\mathcal{F}$ Orthop Res 1984; 2: 328-32.

6 Huddleston A L, Rochwell D, Kulund D N, Harrison R B. Bone mass in lifetime tennis players. FAMA 1980; 244: 1107-9.

7 Dalen N, Laftman P, Ohlsen H, Stromberg L. The effect of athletic activity on bone mass in human diaphysial bone. Orthopaedics 1985; 8: 1139-41.

8 Williams J A, Wagner J, Wasnich R, Heilbrun L. The effect of long-distance running upon appendicular bone mineral content. Med Sci Sports Exerc 1984; 16: 223-7.

9 Lane N E, Bloch D A, Jones H H, Marshall W H, Wood P D, Fries J F. Long distance running, bone density, and D, Fries J F. Long distance running, bon

10 Wolman R L, Reeve J, Clark P, Hesp D, McNally E. Bone mineral density in elite light weight women rowers. $\mathrm{Br} \mathcal{F}$ mineral density in elite light weight

11 Chow R, Harrison J E, Notarius C. Effect of two randomised exercise programmes on bone mass of healthy postmenopausal women. $\operatorname{Br} M e d \mathcal{F} 1987$; 295: 1441-4

12 Dalsky G P, Stocke K S, Ehsani A A, Slatopolsky E, Waldon C L, Birge S J. Weight-bearing exercise training and lumbar bone mineral content in postmenopausa women. Ann Intern Med 1988; 108: 824-8.

13 Pocock N A, Eisman J A, Yeates M G, Sambrook P N, Eberl S. Physical fitness is a major determinant of femoral neck and lumbar spine bone mineral density. $\mathcal{F}$ Clin Invest 1986; 78: 618-21.

14 Chow R K, Harrison J E, Brown C F, Hajek V. Physical fitness effect on bone mass in postmenopausal women. Arch fitness effect on bone mass in postme

15 Bevier W C, Wiswell R A, Pyka G, Kozak K C, Newhall K M, Marcus R. Relationship of body composition, muscle strength, and aerobic capacity to bone mineral density in older men and women. Fournal of Bone Mineral Research 1989; 4: 421-32.

16 Sinaki M, McPhee M C, Hodgson S F, Merritt J M, Offord K P. Relationship between bone mineral density of spine and strength of back extensors in healthy postmenopausal women. Mayo Clin Proc 1986; 61: 116-22.

17 Lanyon L E. Bone loading, exercise, and the control of bone mass: the physiological basis for the prevention of osteoporosis. Bone-Clinical and Biochemical News and Reviews 1989; 6: 19-21.

18 Feicht C B, Johnson T S, Martin B J, Sparkes K E, Wagner $W$ W. Secondary amenorrhoea in athletes. Lancet 1978; ii: $1145-6$.

19 Wolman R L, Harries M G. Menstrual abnormalities in elite athletes. Clin Sports Med 1989; 1: 95-100.

20 Frisch R E, Gotz-Webergen A V, McArthur J W, et al. Delayed menarche and amenorrhoea of college athletes in relation to age of onset of training. $J A M A$ 1981; 246: 1559-63.

21 Wolman R L, Harries M G, Fyfe I. Slipped upper femoral epiphysis in an amenorrhoeic athlete. Br Med f 1989; 299: 720-1.

22 Albright F, Smith P H, Richardson A M. Postmenopausal osteoporosis-its clinical features. $\mathscr{f} A M A$ 1941; 116: 2465-74.

23 Aitken J M, Hart D M, Anderson J B, Lindsay R, Smith D A, Speirs C F. Osteoporosis after oophorectomy for nonmalignant disease in premenopausal women. Br Med $\mathcal{f}$ 1973; ii: 325-8.

24 Lindsay $R$, Hart D M, Abdalla $H$, Al-Azzawi F. Interrelationship of bone loss and its prevention, and fracture expression. In: Christiansen C, Johansen J S, Riis B J, eds. Osteoporosis 1987. Vol 1. Osteopress, 1987: 508-12.

25 Matta W M, Shaw R W, Hesp R, Katz D. Hypogonadism induced by luteinising hormone releasing hormone agonist analogues: effects on bone density in premenopausal analogues: effects on bone density

26 Matta W H, Shaw $R$ W, Hesp R, Evans R. Reversible trabecular bone density loss following induced hypooestrogenism with the GnRH analogue buserelin in premenopausal woman. Clin Endocrinol 1988; 29: 45-51.

27 Klibanski A, Neer R M, Beitins I Z, Chester Ridgway E, Zervas N T, McArthur J W. Decreased bone density in hyperprolactinemic women. $N$ Engl f Med 1980; 303: $1511-4$.

28 Cann C E, Martin M C, Genant H K, Jaffe R B. Decreased spinal mineral content in amenorrheic women. $\mathscr{f} A M A$ 1984; 251: 626-9.

29 Rigotti N A, Nussbaum S R, Herzog D B, Neer R M. Osteoporosis in women with anorexia nervosa. $N$ Engl $\mathcal{f}$ Med 1984; 311: 1610-6.

30 Szmuckler G I, Brown S W , Parsons V, Darby A. Premature loss of bone in chronic anorexia nervosa. Br Med $\mathcal{F} 1985$; 290: $26-7$.

31 Treasure J L, Russell G F M, Fogelman I, Murby B. Reversible bone loss in anorexia nervosa. $\mathrm{Br} \mathrm{Med} \mathcal{F}$ 1987; 295: 474-5.

32 Drinkwater B L, Nilson K, Chesnut C H, Bremner W J, Shainholtz S, Southworth M B. Bone mineral content of amenorrheic and eumenorrheic athletes. $N$ Engl $\mathcal{Y}$ Med 1984; 311: 277-81.

33 Lindberg J S, Fears W B, Hunt M M, Powell M R, Boll D, Wade C E. Exercise-induced amenorrhoea and bone density. Ann Interm Med 1984; 101: 647-8.

34 Marcus $R$, Cann C, Madvig $P$, et al. Menstrual function and bone mass in elite women distance runners. Ann Intern Med 1985; 102: 158-63.

35 Cann C E, Genant H K, Ettinger B, Gordan G S. Spinal mineral loss in oophorectomized women: determination by computerized tomography. FAMA 1980; 244: 2056-9.

36 Jones K P, Ravnikar V A, Tulchinsky D, Schiff I. Comparison of bone density in amenorrheic women due to athletes, weight loss, and premature menopause. Obstet Gynecol 1985; 66: 5-8.

37 Drinkwater B L, Nilson K, Ott S, Chesnut C H. Bone mineral density after resumption of menses in amenorrheic athletes. FAMA 1986; 256: 380-2.

38 Lindberg I S, Powell M R, Hunt M M, Ducey D E, Wade C E. Increased vertebral bone mineral in response to reduced exercise in amenorrheic runners. West $\mathcal{F}$ Med 1987; 146: $39-42$.

39 Deuster P A, Kyle S B, Moser P B, Vigersky R A, Singh A, Schoomaker E B. Nutritional intakes and status of highly trained amenorrheic and eumenorrheic women runners. trained amenorrheic and eument

40 Parfitt A M. Dietary risk factors for age-related bone loss and fractures. Lancet 1983 2: 1181-5.

41 Cann C E, Genant H K, Kolb F O, Ettinger B. Quantitative computed tomography for prediction of vertebral fracture risk. Bone $1985 ; 6$ : 1-7. 